\title{
Main line patterns of palmar dermatoglyphics in female breast cancer patients
}

\begin{abstract}
Aim: Breast cancer incidence and mortality rates represent a serious socio-medical challenge worldwide. The present study illustrates some dermatoglyphic differences between breast cancer females and healthy controls.

Material and methods: We examined 82 females with clinically, histologically and mammographically proved breast cancer and 60 healthy controls. Conventional palmoscopic features including the four main palmar lines A, B, C, and D were examined by the method described by Cummins \& Midlo.

Results: We established statistically significant differences between both groups concerning the frequencies of main palm line $\mathrm{A}\left(\chi^{2}=14,96 ; \mathrm{p}=0,0001\right)$, A $3(+4)(\mathrm{p}<0,001)$, A $5\left(5^{\circ}+5^{\circ}+6\right)(p<0,001)$, main palm line $\mathrm{D}\left(\chi^{2}=32,86 ; \mathrm{p}=0,0001\right)$, D $9(+10)(\mathrm{p}<0,0001)$ and D 11(+12+13) $(\mathrm{p}<0,0001)$ of the left hand. There were statistically reliable differences between these groups in terms of the frequencies of main palm line $\mathrm{A}\left(\chi^{2}=22,51 ; \mathrm{p}=0,0001\right)$, A 3(+4) $(\mathrm{p}<0,001)$, A $5\left(5^{6}+5^{“}+6\right)(\mathrm{p}<0,001)$, main palm line $\mathrm{D}\left(\chi^{2}=15,65 ; \mathrm{p}=0,0001\right)$, D $9(+10)(\mathrm{p}<0,001), \mathrm{D} 11(+12+13)(\mathrm{p}<0,001)$, main line B (absence) $(\mathrm{p}<0,05)$ as well as of main line $\mathrm{C}$ (absence) $(\mathrm{p}<0,02)$ of the right hand.
\end{abstract}

Conclusion: We concluded that dermatoglyphic investigations of the main palmar lines could serve as an additional valuable prognostic tool for risk stratification in women suspected for breast cancer.

Keywords: breast cancer, dermatoglyphics, main palmar lines A, B, C, D, risk prognostication
Volume 5 Issue 6 - 2018

\section{Yaneva Galina,' Gergana Ingilizova²}

'Department of Biology, Medical University of Varna, Bulgaria 2Vita Multidisciplinary Hospital for Active Treatment, Sofia, Bulgaria

Correspondence: Yaneva Galina, Department of Biology, Faculty of Pharmacy, Medical University of Varna, Varna 9003, 55 Marin Drinov Street, Bulgaria, Email galina.yanavaa@gmail.com

Received: October II, 2018 | Published: November 16, 2018

\section{Introduction}

In the recent decades, several articles deal with dermatoglyphic investigations in breast cancer patients. ${ }^{2-6}$ Fingerprint research prevails over palmar dermatoglyphics. However, specific palmar patterns such as ridge count, ATD angles and A, B, C and D main lines represent an integral component of diagnostic and prognostic armamentarium in female breast cancer patients.

Our purpose was to examine the differences between breast cancer females and healthy controls in terms of the A, B, C, and D main line palmar characteristics as a possible prognostic tool for breast cancer risk evaluation.

\section{Material and methods}

Our study covered 82 females with clinically, histologically and mammographically proved breast cancer and 60 healthy controls of Bulgarian ethic origin. Their age distributions in 10-year intervals were juxtaposed in Figure 1. The patients were hospitalized and operated on in the Clinic of Thoracic Surgery, St. Marina University Hospital of Varna, during the period between January 1, 2014 and December 31, 2017.

Conventional palmoscopic features including the four main palmar lines A, B, C, and D were examined by the method described by Cummins \& Midlo. ${ }^{1}$ Data were processed by means of variation analysis (Student t-test) and $\chi^{2}$ test using SPSS software, version 19.

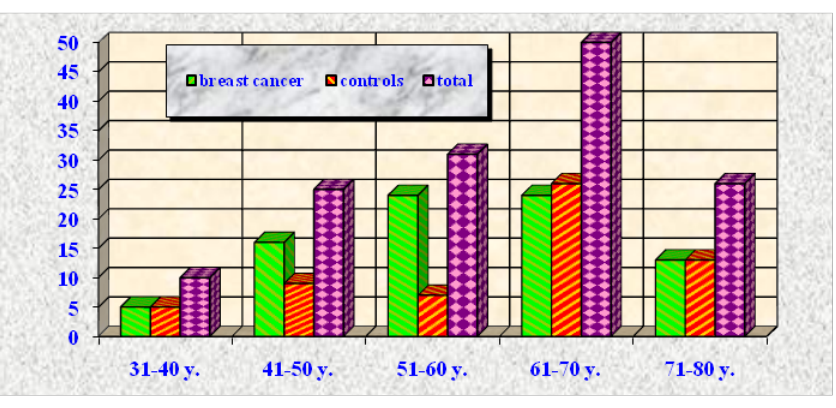

Figure I Age distributions of breast cancer patients and healthy controls.

\section{Results and discussion}

The results from $\chi^{2}$ test demonstrated statistically significant differences between both groups concerning the frequencies of main palm line A $\left(\chi^{2}=14,96 ; \mathrm{p}=0,0001\right)$, A $3(+4)(\mathrm{t}=4,005 ; \mathrm{p}<0,001)$, A $5\left(5^{6}+5^{\prime c}+6\right)(\mathrm{t}=4,005 ; \mathrm{p}<0,001)$ (Figure 2$)$, main palm line $\mathrm{D}\left(\chi^{2}=32,86\right.$; $\mathrm{p}=0,0001), \mathrm{D} 9(+10)(\mathrm{t}=6,286 ; \mathrm{p}<0,0001)$ and $\mathrm{D} 11(+12+13)(\mathrm{t}=6,298$; $\mathrm{p}<0,0001$ ) (Figure 3 ) of the left hand.

The frequencies of the main lines B and $\mathrm{C}$ of the left hand did not differ statistically reliably between breast cancer females and healthy controls $\left(\chi^{2}=2,00 ; p=0,156\right.$ and $\chi^{2}=2,21 ; p=0,137$, respectively).

The results from $\chi^{2}$ test demonstrated statistically reliable 
differences between both groups in terms of the frequencies of main palm line A $\left(\chi^{2}=22,51 ; \mathrm{p}=0,0001\right), \mathrm{A} 3(+4)(\mathrm{t}=4,922 ; \mathrm{p}<0,001)$, A $5\left(5^{6}+5^{6}+6\right)(\mathrm{t}=4,922 ; \mathrm{p}<0,001)$ (Figure 4$)$, main palm line $\mathrm{D}$ $\left(\chi^{2}=15,65 ; \mathrm{p}=0,0001\right), \mathrm{D} 9(+10)(\mathrm{t}=4,185 ; \mathrm{p}<0,001), \mathrm{D} 11(+12+13)$ $(\mathrm{t}=4,326 ; \mathrm{p}<0,001)$, main line $\mathrm{B}$ (absence) $(\mathrm{t}=2,056 ; \mathrm{p}<0,05)$ as well as of main line $\mathrm{C}$ (absence) $(\mathrm{t}=2,42 ; \mathrm{p}<0,02)$ (Figure 5$)$ of the right hand.

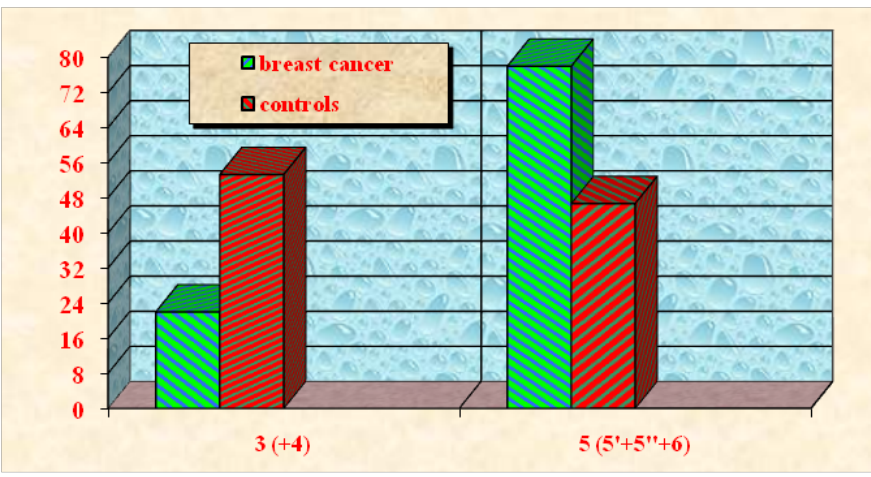

Figure 2 Main palm line A frequency of the left hand in breast cancer females and healthy controls.

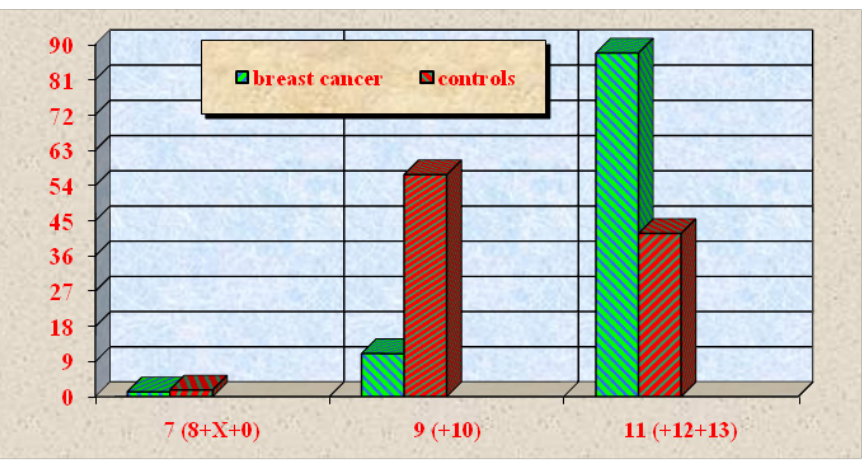

Figure 3 Main palm line D frequency of the left hand in breast cancer females and healthy controls.

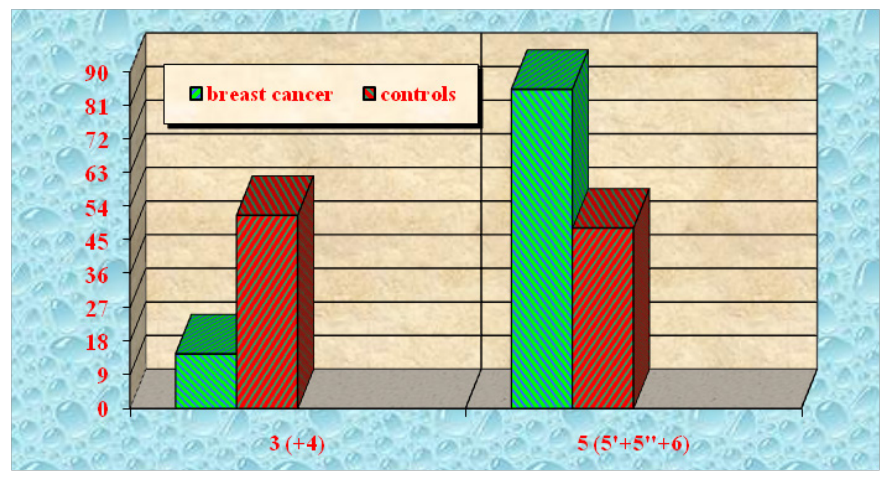

Figure 4 Main palm line A frequency of the right hand in breast cancer females and healthy controls.

The results from a palmoscopic investigation of 48 bilateral palmar prints of breast cancer patients from different hospitals of Madhya Pradesh, India, demonstrated that the main line formula of 11.9.7 was less frequent $(23,95 \% ; 33,33 \%$ in the right and $14,58 \%$ in the left hand) than that in healthy controls $(27,08 \% ; 25,00 \%$ and
$29,16 \%$, respectively). ${ }^{7}$ This difference was, however, statistically insignificant.

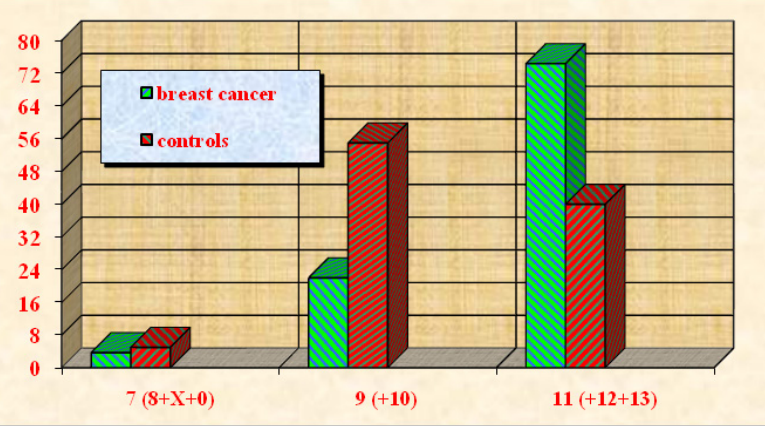

Figure 5 Main palm line D frequency of the right hand in breast cancer females and healthy controls.

The comparative study of palmar traits of 25 breast cancer female patients and 25 healthy controls of the same ethnic origin in India showed more aberrations of main palmar line $\mathrm{C}$ in the patients than in the controls. ${ }^{8}$ A scale for dermatoglyphic assessment was suggested that could be applied in the preliminary mass screening for identification of women bearing a high breast cancer risk.

A template-based image preprocessing as a functional plug-in of the dermatoglyphics analysis and detection system was developed. ${ }^{9}$ It included histogram redistribution, ridge orientation, and skeletonization for automatic identification of ridges and triradiuses. This system could be applied as an auxiliary diagnostic tool for mammary cancer and other hereditary diseases.

\section{Conclusion}

Based on our own data demonstrating statistically significant differences between breast cancer patients and healthy women concerning the frequencies of main palmar lines A and D as well as on scanty literature data available we could draw the conclusion that dermatoglyphic research dealing with these main palmar lines deserves a particular attention as an additional valuable prognostic tool for risk stratification in women suspected for breast cancer.

\section{Acknowledgements}

None.

\section{Conflict of interest}

The authors declare there is no conflict of interest.

\section{References}

1. Cummins H, Midlo C. Finger prints palms and soles. An introduction in dermatoglyphics. Blakinston, Philadelphia, New York: Reprinted Dower; 1961:319.

2. Sridevi NS, Delphine Silvia CR, Kulkarni R, et al. Palmar dermatoglyphics in carcinoma breast of Indian women. Rom J Morphol Embryol. 2010;51(3):547-550.

3. Sariri E, Kashanian M, Vahdat M, et al. Comparison of the dermatoglyphic characteristics of women with and without breast cancer. Eur $J$ Obstet Gynecol Reprod Biol. 2012;160(2):201-204.

4. Raizada A, Johri V, Ramnath T, et al. A cross-sectional study on the palmar dermatoglyphics in relation to carcinoma breast patients. J Clin Diagn Res. 2013;7(4):609-612. 
5. Lavanya J, Vijayakumar J, Prathap S, et al. Digital and palmar dermal ridge patterns in population with breast carcinoma. Biomedicine (India). 2014;34(3):315-321.

6. Madhavi D, Dorairaj S, Dorairaj SSJ, et al. Dermatoglyphic study in breast carcinoma patients. Int J Sci Res. 2016;5(10):837-840.

7. Gautam R, Mishra AM, Chaubey R. Dermatoglyphic studies and its application in disease diagnosis with special reference to the breast cancer Man in India. 2004;84(1-2):109-112.
8. Bhardwaj DN, Guleria SS, Shrivastava PK, et al. Dermatoglyphic studies in breast cancer. Acta Anthropogenet. 1978;2(4):9-24.

9. Qiao Y, Li Z, Wang Q, et al. Identification of palm print using dermatoglyphics analysis and detection system. Med Eng Phys. 2005;27(3):229235 